\title{
Percepções de docentes e discentes sobre uso educativo de mídias sociais
}

\section{Perceptions of teachers and students about the educational use of social media}

Arquimedes Pessoni ${ }^{1}$, Marco Akerman ${ }^{2}$

'Universidade Municipal de São Caetano do Sul (USCS) - São Caetano do Sul (SP), Brasil.

${ }^{2}$ Faculdade de Medicina do ABC (FMABC) - Santo André (SP), Brasil.

DOI: http://dx.doi.org/10.7322/abcshs.v40i3.792

\section{RESUMO}

Introdução: $\mathrm{O}$ uso das redes sociais digitais vem sendo um importante aliado nas atividades de ensino e aprendizagem. Objetivo: A pesquisa avaliou a percepção dos alunos e professores sobre o uso dessas novas ferramentas em ambiente educacional. Métodos: Foram distribuídos dois tipos de questionários online a alunos e professores de cursos de Saúde de duas instituições de ensino superior do ABC Paulista, respondidos por 55 alunos e 19 professores. Com base nesses dados, identificamos afirmações qualitativas para avaliar percepções dos dois grupos sobre o uso de redes sociais digitais em ambiente educacional. Resultados: Observou-se que os alunos estão mais familiarizados com as ferramentas digitais e que parte dos docentes as conhece, mas não as utilizam. O Youtube e o Facebook foram as mídias mais referenciadas e usadas por ambos os públicos. Os alunos apontaram formas de utilização extraclasse para as ferramentas digitais. Conclusão: Mídias sociais podem ser utilizadas como ferramentas educativas, mas os professores precisam ser sensibilizados e capacitados para o uso; alunos podem encontrar opções de compartilhamento e produção de conhecimento coletivo no ambiente virtual de educação em saúde.

Palavras-chave: educação; comunicação; rede social; apoio social; metodologia.

\section{ABSTRACT}

Introduction: The use of online social networks has been an important ally in the teaching and learning activities. Objective: The study examined the perception of students and teachers on the use of these new tools in the educational environment. Methods: Two types of online questionnaires were distributed to students and teachers of Health programs of two higher education institutions in ABC Paulista, and 55 students and 19 teachers answered the questions. Based on these data, qualitative statements were identified to assess perceptions of the two groups on the use of online social networks in the educational environment. Results: It was observed that students are more familiar with digital tools and that teachers know about them, but do not use them. Youtube and Facebook were the most referenced media and used by both audiences. Students suggested forms of extracurricular use of digital tools. Conclusion: Social media can be used as educational tools, but teachers need to be sensitized and trained to use them. Students can find options and share collective knowledge production in the virtual environment of health education.

Keywords: education; communication; social networking; social support; methodology. 


\section{INTRODUÇÃO}

A realidade do ensino e aprendizagem ganha novos contornos a partir do uso das novas tecnologias de comunicação. As aulas tradicionais, fundamentadas na figura do professor como centro das atenções e detentor do saber, com o advento da Internet passam a ter nessa inteligência coletiva uma ferramenta importante de pesquisa e espaço de relacionamento que vai além da sala de aula. Um conteúdo ministrado em sala de aula pelo professor, por meio de compartilhamento do saber, recebe de forma colaborativa outras contribuições. $\mathrm{O}$ aluno tem mais opções de busca de informação sobre o conteúdo dado e seu aprendizado pode continuar mesmo à distância.

Em 2014, de acordo com levantamento realizado pela Secretaria de Comunicação Social da Presidência da República, praticamente a metade dos brasileiros, $48 \%$, usavam internet. O hábito de uso da internet também é intenso, uma vez que os usuários das novas mídias ficam conectados, em média, 4h59 por dia durante a semana e $4 \mathrm{~h} 24$ nos finais de semana. Entre os usuários com ensino superior, $72 \%$ acessam a internet todos os dias, com uma intensidade média diária de 5h41, de segunda a sexta-feira. Entre os internautas, $92 \%$ estão conectados por meio de redes sociais, sendo as mais utilizadas o Facebook (83\%), o Whatsapp (58\%) e o Youtube $(17 \%)^{1}$.

Do ponto de vista da comunicação, a mudança do paradigma se dá com a crescente digitalização do saber, criação de portais de pesquisa e a ampliação de possibilidades de busca de conteúdo por parte de alunos e também de professores. Com o surgimento das redes sociais virtuais, os alunos permanecem conectados em comunidades além do horário de aula. Muitos encontram ali com o apoio dos docentes - no espaço de grupos fechados, criados para este fim, uma continuação da sala de aula.

Os professores que acompanham o progresso tecnológico já perceberam que, ao invés de ver a tecnologia como uma ameaça, podem tê-la como aliada no campo do ensino e aprendizagem.

Recuero $^{2}$ define redes sociais como interações que acontecem entre as pessoas e derivam em grupos sociais, conectados por interesses afins. Ela ressalta que, para entender como funcionam e derivam os laços sociais, é necessário observar o todo como um sistema no qual os indivíduos estão ligados e suas ações afetam o resultado final.

Em se tratando de redes sociais na internet, existem dois componentes dessa relação que possibilitam o funcionamento do sistema: os atores e conexões. A autora ainda complementa: "Rede social é gente, é interação, é troca social. É um grupo de pessoas, compreendido através de uma metáfora de estrutura, a estrutura da rede".

Segundo Mondini et al. ${ }^{3}$, as redes sociais digitais vêm modificando as formas de comunicação e relacionamento das pessoas, afetando com isso também as instituições de ensino superior (IES). O estudo realizado pelos autores com IES em Santa Catarina demonstrou um alto índice de adesão às redes sociais digitais como estratégia nos processos de ensino/aprendizagem e comunicação institucional.
Com a chegada da Geração Y (aqueles nascidos após 1978) às salas de aula, cada vez mais os professores são forçados a repensar no modelo de ensino, tornando aulas mais dinâmicas e agregando tecnologia ao saber. Verificar como esta mudança no relacionamento entre alunos e professores, por meio do uso das redes sociais virtuais - especificamente o Facebook (aquele que quantitativamente teve maior crescimento nos últimos anos e o maior número de aplicativos para esse fim) - afeta o processo de ensino-aprendizagem como meio de comunicação nos cursos de Saúde pode contribuir para projetar novas formas de compartilhamento de saberes e, consequentemente, melhor comunicação entre discentes e docentes por meio das novas tecnologias.

Diversos autores têm se debruçado sobre a questão do impacto do uso de redes sociais por alunos e professores. Shah et al. ${ }^{4}$ buscaram identificar benefícios do uso de mídias sociais virtuais no ganho de capital social e verificar o impacto na performance acadêmica dos pesquisados. Magro et al..$^{5}$ tinham como objetivo verificar junto a estudantes universitários americanos como o Facebook poderia ser utilizado como ferramenta pedagógica. Hew $^{6}$ se propôs a examinar como alunos fazem uso do Facebook para engajar a sala de aula em atividades colaborativas e mostrar como esta rede pode ser utilizada como ferramenta informal para organizar experiências em sala e explorar os fatores que promovem este tipo de uso.

$\mathrm{Choi}^{7}$ estudou experiências de implementação do Facebook em grupos para promover a colaboração dos estudantes, e Barczyk e Duncan ${ }^{8}$ buscaram determinar a atividade de alunos e percepções sobre cursos em que o Facebook tem sido incorporado.

Com foco nos docentes, Chatterjee ${ }^{9}$ propôs estudar os antecedentes e consequências da utilização da mídia social por professores universitários. Roblyer et al. ${ }^{10}$ procuram identificar as diferenças na adoção do Facebook por estudantes e docentes da faculdade do ponto de vista pessoal e educacional. Bicen e Uzunboylu ${ }^{11}$ tentaram descobrir como o Facebook e a web 2.0 criavam um efeito positivo quando usados na educação para investigar a opinião dos professores sobre o ambiente de aprendizado online.

\section{MÉTODOS}

Para avaliar as percepções dos alunos e professores da área da saúde sobre o uso das redes sociais virtuais nas atividades de ensino/aprendizagem, foram desenvolvidos dois questionários online, com perguntas abertas e fechadas, abrigados na plataforma GoogleDocs e distribuídos por e-mail aos docentes e discentes de duas instituições universitárias no mês de abril de 2013. Compuseram o universo da pesquisa os docentes e discentes da USCS e FMABC dos cursos de graduação da área de Saúde que, após informados sobre a pesquisa e seus procedimentos, aprovaram a participação com o preenchimento do Termo de Consentimento Livre e Esclarecido (TCLE), elaborado digitalmente de acordo com as orientações da Resolução 196/96 da 
Comissão Nacional de Ética em Pesquisa (CONEP). O estudo foi pautado pela amostragem por acessibilidade ou por conveniência.

As questões foram respondidas por 55 alunos e 19 professores e devidamente analisadas quantitativa e qualitativamente. O presente estudo foi submetido à apreciação do Comitê de Ética em Pesquisa sob o protocolo 33/12.

\section{RESULTADOS E DISCUSSÃO}

Dos alunos respondentes, $86 \%$ eram do sexo feminino e $14 \%$ masculino. A faixa etária mais presente na pesquisa era representada por estudantes entre 19 e 23 anos (68\%). A maior parte dos alunos era da Faculdade de Medicina do ABC (56\%), sendo 44\% alunos da Universidade Municipal de São Caetano do Sul, divididos entre os cursos: 35\% alunos de Medicina, 20\% de Farmácia, 15\% de Enfermagem, 11\% de Nutrição, 7\% de Fisioterapia, 6\% de Educação Física e 6\% de Terapia Ocupacional.

Indagados sobre grau de conhecimento de alguns serviços e aplicações da Web, os alunos responderam conhecer bem as seguintes ferramentas Facebook (91\%), Twitter (80\%), Youtube (80\%), Orkut (71\%), Skype (64\%) e Google+ (36\%). Declararam desconhecer ou ter pouco conhecimento das ferramentas/aplicativos Foursquare (69\%), Slideshare (65\%), Tumblr (60\%) e LinkedIn (58\%). Questionados sobre até que ponto usam as aplicações/serviços citadas anteriormente para complementar a sua aprendizagem nas aulas, $80 \%$ indicaram utilizar o Facebook, $78 \%$ citaram o Youtube e 33\% apontaram o Skype para este fim. Sobre a utilidade das ferramentas digitais para fins de estudo, os alunos citaram como importantes o Youtube (96\%), o Facebook (78\%) e os Blogs (62\%). Especificamente os alunos de Medicina informaram conhecer o Facebook (95\%), Skype (60\%), Orkut (80\%) e Youtube (100\%), e apenas 15\% dos estudantes de Medicina informaram nunca usar o Facebook para complementar atividades de aprendizagem.

Sobre as vantagens de usar as tecnologias listadas anteriormente para complementar a aprendizagem nas aulas, foram citadas, pela ordem de importância: "melhorar minha aprendizagem", "melhorar minha interação com meus colegas", "melhorar minha interação com os professores", "melhorar minhas notas" e "melhorar minha capacidade de escrita". Em relação às tecnologias da Web 2.0 que usam mais frequentemente (ou pretendem usar em breve) com o objetivo de complementar a sua aprendizagem nas salas de aula, foram registradas, pela ordem de importância, o Youtube, o Facebook, o Google+ e os Blogs. $45 \%$ dos alunos de Medicina acreditam que o Facebook é muito útil em suas atividades de estudo, 35\% referenciam o Google+ e 40\% citam como muito útil o Youtube.

Dos alunos que participaram da pesquisa, 67\% concordam (parcial ou totalmente) que tencionam usar Web 2.0 no próximo semestre para melhorar a aprendizagem; $91 \%$ concordam (parcial ou totalmente) que as tecnologias Web 2.0 são úteis no trabalho acadêmico (no caso dos alunos de Medicina, 100\% concordam com essa afirmação); 69 acreditam que há mais vantagens do que desvantagens em usar Web 2.0; 81\% acreditam ser fácil integrar tecnologias Web 2.0 no ambiente de aprendizagem; $81 \%$ sentem que usar Web 2.0 ajuda a aprender mais sobre as matérias da faculdade; $62 \%$ concordam que usar a Web 2.0 pode melhorar a satisfação com as disciplinas; $66 \%$ pensam que usar a Web 2.0 pode melhorar as notas; $80 \%$ acreditam que, de modo a aprender melhor as matérias, irão usar tecnologias de Web 2.0 para complementar a aprendizagem nas aulas; $47 \%$ concordam (parcial ou totalmente) que seus colegas pensam que se beneficiarão se usarem Web 2.0 na aprendizagem acadêmica; $76 \%$ confirmam que seus colegas usam tecnologias Web 2.0 para complementar a aprendizagem nas aulas; $60 \%$ acreditam que alguns professores pensam que é importante que os alunos usem Web 2.0 para complementar a aprendizagem nas aulas; $69 \%$ afirmam que usar tecnologia 2.0 só depende deles mesmos e $80 \%$ concordam ter conhecimento e capacidade para usar tecnologias Web 2.0. Especificamente entre os alunos de Medicina, 35\% acreditam que o Facebook pode ajudar a melhorar sua interação com os professores e $45 \%$ acreditam que essa ferramenta pode ajudar em sua aprendizagem.

Daqueles que fazem uso do Facebook, 49\% dedicam de 1 a 5 horas, em média, por semana a esta rede social virtual; $17 \%$ ficam mais de 20 horas por semana no Facebook; 15\%, entre 6 e 10 horas; $15 \%$, entre 11 e 15 horas e $4 \%$, entre 16 e 20 horas diante da tela. $64 \%$ dos alunos acessam mais de uma vez por dia o Facebook. Entre os principais motivos para usar o Facebook, os mais citados pelos alunos são: conversar com amigos e compartilhar informações. Apenas 7\% citaram utilizar como extensão do curso ou sala de aula. Indagados sobre usar o Facebook para complementar as aulas, 54\% se referiram a utilizar o Facebook para esclarecer dúvidas e postar conteúdos abordados em sala de aula. Perguntados sobre as ferramentas Web 2.0 utilizadas pelos seus professores em sala de aula, a mais lembrada foi o Youtube, referenciada por $60 \%$ dos alunos, seguida do Facebook, com $42 \%$. São justamente essas duas redes sociais digitais as mais valorizadas pelos estudantes quando questionados em que medida valorizam o uso das ferramentas Web 2.0 nas atividades de ensino, com $66 \%$ dos respondentes citando o Youtube e $49 \%$ referenciando o Facebook. $87 \%$ dos alunos acreditam ser o Youtube compatível com suas estratégias de estudo e, no caso do Facebook, $42 \%$ acreditam ser pouco compatível e o mesmo percentual sugere ser muito compatível seu uso para esse fim. Sobre a quantidade de amigos que mantêm no Facebook, especificamente os alunos de Medicina referenciaram como menor quantidade 150 amigos e com maior quantidade 1.450 .

Mais da metade dos alunos (55\%) concordam que o Facebook faz parte de suas atividades diárias, embora $34 \%$ não sintam satisfação em poder dizer que estão inseridos nessa rede. Embora $27 \%$ concordam que se sintam parte da comunidade de usuários do Facebook, 34\% discordam que sentem-se "desligados" quando ficam algum tempo sem acessar esta rede social. $49 \%$ dos alunos que participam da pesquisa concordam completamente que achariam 
ruim se o Facebook deixasse de existir e $45 \%$ dos estudantes pesquisados acreditam que esta ferramenta fomenta as relações entre os colegas de turma e promove o debate. $47 \%$ dos respondentes concordam totalmente que o Facebook transmite informações sobre os materiais e recursos necessários para as aulas, $56 \%$ acreditam que a rede transmite os avisos/novidades da escola, da turma e do trabalho em aula e $49 \%$ alegam que serve para distribuir os trabalhos de casa e da aula. $64 \%$ concordam plenamente que o Facebook permite formar grupos acadêmicos que partilham os mesmos interesses, $67 \%$ afirmam que a ferramenta aceita partilhar informações sobre as disciplinas ou trabalhos escolares e $60 \%$ sugerem que esta rede social permite organizar os trabalhos em grupo. Embora $43 \%$ dos alunos acreditem que, durante a aprendizagem, o Facebook permite usar os recursos multimídia (vídeos, animações, etc), apenas $38 \%$ concordam plenamente que a ferramenta permite obter os materiais e as informações necessários para a aprendizagem.

Indagados se o Facebook fomentaria as relações entre professores e alunos, $24 \%$ dos estudantes discordaram totalmente, enquanto $26 \%$ concordaram totalmente. Sobre esse mesmo assunto, $55 \%$ dos alunos acreditam que ter um professor como amigo em sua rede social virtual seja bom; $43 \%$ são indiferentes e para $2 \%$ isso é ruim. No caso específico dos alunos de Medicina, 55\% são indiferentes, $40 \%$ acha bom e apenas $5 \%$ destacam fatores positivos e negativos nesse relacionamento. Entre os motivos positivos citados estão o aumento da proximidade entre aluno e professor, ser uma forma rápida de tirar dúvidas, manter contato mesmo após o término do curso, poder saber o que o que professor pensa sobre os mais diversos assuntos e acompanhar aqueles docentes que compartilham muitos links interessantes, que somam bastante no conhecimento. E como os alunos estão sempre ligados ao Facebook, compartilham essas informações por achá-las relevantes. Entre os fatores negativos citados pelos alunos ao ter um professor como amigo no Facebook estão o de restringir a liberdade de expressão entre os colegas de faculdade, já que o professor pode intrometer-se nas intimidades da turma. Um dos alunos alegou que essa proximidade pode ser ruim, pois em certos aspectos da vida pessoal é estranho que o professor saiba do aluno e vice-versa.

Na tabulação do questionário respondido pelos docentes, $62 \%$ eram do sexo feminino e $38 \%$ do sexo masculino. A maioria (64\%) estava na faixa etária entre 30 e 49 anos, sendo que a maior parte (32\%) tinha entre 20 e 29 anos de experiência como docente. 55\% dos respondentes eram professores da Universidade Municipal de São Caetano do Sul e $45 \%$ da Faculdade de Medicina do ABC. Em relação ao curso em que lecionavam a maior parte de sua carga horária, 23\% indicaram Farmácia, 19\% Educação Física, 19\% Fisioterapia, 19\% Medicina, 10\% Enfermagem e 10\% Nutrição. A maior parte dos professores (71\%) tinha a Saúde como área científica de formação primeira.

Sobre o grau de conhecimento a respeito de serviços e aplicações na Web, os docentes responderam de acordo com a Tabela 1.

Especificamente entre os professores do curso de Medicina, $100 \%$ indicaram utilizar o Facebook, LinkedIn e Youtube, 50\% o Google+ e 75\% o Skype.
Indagados se nos últimos semestres teriam utilizado as aplicações/serviços indicados na Tabela 1 no âmbito de sua atividade letiva/pedagógica, sobre Blogs, $80 \%$ nunca usaram e 20\% usaram algumas vezes; o Facebook, $48 \%$ usaram algumas vezes ou muito, sobre o Foursquare, $95 \%$ nunca usaram ou não sabem; o Google+, $52 \%$ não sabem ou nunca usaram e $48 \%$ usaram muito ou algumas vezes; o LinkedIn, $86 \%$ não sabem ou nunca usaram; o Skype, $81 \%$ não sabem ou nunca usaram; o Slideshare, $74 \%$ não sabem ou nunca usaram; o Orkut, $100 \%$ nunca usaram, assim como o Twitter e o Tumblr, e quanto ao Youtube, $76 \%$ usaram algumas vezes ou muito. No recorte específico dos professores de Medicina, 25\% alegaram ter utilizado algumas vezes o Facebook em alguma atividade letiva/pedagógica e 50\% citaram o Google+, Skype e Youtube.

Em relação à possibilidade de utilizar essas ferramenta nos próximos semestres no âmbito da sua atividade letiva/pedagógica, apenas o Facebook (72\%), o Google+ (72\%) e o Youtube (66\%) foram indicados como possibilidade de uso. Especificamente para os docentes de Medicina, 75\% indicaram a possibilidade de utilizar o Facebook em atividades pedagógicas, 50\% citaram o Google+, o Youtube e o Skype, e 25\%, o LinkedIn.

Para identificar em que medida os docentes seriam capazes de explicar as vantagens/desvantagens associadas ao uso de cada uma das aplicações/serviços citados na Tabela 1 em suas atividades letivas e pedagógicas, reunimos na Tabela 2 suas respostas.

Tabela 1: Conhecimento de serviços e aplicações na Web pelos docentes

\begin{tabular}{|l|c|c|c|c|c|}
\hline Ferramenta & $\begin{array}{c}\text { Não } \\
\text { sei }\end{array}$ & $\begin{array}{c}\text { Nunca } \\
\text { uso }\end{array}$ & $\begin{array}{c}\text { Raramente } \\
\text { uso }\end{array}$ & $\begin{array}{c}\text { Uso algumas } \\
\text { vezes }\end{array}$ & $\begin{array}{c}\text { Uso } \\
\text { muito }\end{array}$ \\
\hline Blogs & $5 \%$ & $38 \%$ & $28 \%$ & $24 \%$ & $5 \%$ \\
\hline Facebook & 0 & $14 \%$ & $5 \%$ & $24 \%$ & $57 \%$ \\
\hline Foursquare & $42 \%$ & $48 \%$ & 0 & $5 \%$ & $5 \%$ \\
\hline Google+ & 0 & $24 \%$ & $14 \%$ & $38 \%$ & $24 \%$ \\
\hline Linkedln & 0 & $42 \%$ & $14 \%$ & $34 \%$ & $10 \%$ \\
\hline Skype & $5 \%$ & $19 \%$ & $24 \%$ & $38 \%$ & $14 \%$ \\
\hline Slideshare & $34 \%$ & $42 \%$ & 0 & $19 \%$ & $5 \%$ \\
\hline Orkut & $5 \%$ & $90 \%$ & $5 \%$ & 0 & 0 \\
\hline Tumblr & $58 \%$ & $42 \%$ & 0 & 0 & 0 \\
\hline Twitter & $10 \%$ & $80 \%$ & $10 \%$ & 0 & 0 \\
\hline Youtube & 0 & $5 \%$ & $19 \%$ & $42 \%$ & $34 \%$ \\
\hline & & & & & \\
\hline
\end{tabular}

Tabela 2: Conhecimento de vantagens/desvantagens associadas a serviços e aplicações na Web pelos docentes em atividades letivas/pedagógicas

\begin{tabular}{|l|c|c|c|}
\hline Ferramenta & $\begin{array}{c}\text { Desconheço } \\
\text { a ferramenta }\end{array}$ & $\begin{array}{c}\text { Não saberia } \\
\text { explicar totalmente }\end{array}$ & $\begin{array}{c}\text { Saberia } \\
\text { explicar muito } \\
\text { bem }\end{array}$ \\
\hline Blogs & $14 \%$ & $38 \%$ & $48 \%$ \\
\hline Facebook & $5 \%$ & $23 \%$ & $72 \%$ \\
\hline Foursquare & $62 \%$ & $38 \%$ & 0 \\
\hline Google+ & $10 \%$ & $42 \%$ & $48 \%$ \\
\hline Linkedln & $15 \%$ & $52 \%$ & $33 \%$ \\
\hline Skype & $10 \%$ & $42 \%$ & $48 \%$ \\
\hline Orkut & $20 \%$ & $55 \%$ & $25 \%$ \\
\hline Tumblr & $70 \%$ & $25 \%$ & $5 \%$ \\
\hline Twitter & $35 \%$ & $45 \%$ & $20 \%$ \\
\hline Youtube & 0 & $20 \%$ & $80 \%$ \\
\hline & & & \\
\hline
\end{tabular}


Questionados sobre a utilidade das aplicações/serviços da Tabela 2 em suas atividades de ensino, o Facebook foi visto como muito útil por $38 \%$ dos docentes, o Google+ também foi visto como muito útil (50\%) e o Youtube foi considerado como o mais útil entre os aplicativos, com $81 \%$ das respostas positivas. Dos docentes que possuem conta no Facebook, $48 \%$ deles responderam que gastam entre 1 e 5 horas por semana no aplicativo e $62 \%$ dos docentes alegam acessar uma ou várias vezes aquela rede social diariamente. Entre os motivos mais citados para utilizar o Facebook, os mais referenciados foram conversar com amigos, compartilhar informações, acompanhar atividades dos amigos e manter contato com familiares. 24\% dos docentes relataram usar o Facebook como extensão do curso/sala de aula para, entre outras atividades, compartilhar a aula, esclarecer dúvidas dos alunos, criar grupo de estudos e postar conteúdos abordados em sala de aula. Indagados sobre as vantagens de usar o Facebook em sua atividade pedagógica/letiva, os professores citaram "melhorar a dinâmica da turma", "melhorar a interação com os alunos", "melhorar a satisfação dos alunos com a disciplina”. Também ressaltaram a questão da veiculação de informações rapidamente e ser mais rápido que e-mail.

Sobre o uso das ferramentas da Tabela 1 pelos colegas de profissão, a maior parte dos docentes desconhece se são utilizadas, com exceção do Youtube e dos Blogs, citados por 33\% dos respondentes como sendo ferramenta de uso didático dos professores. Também o Youtube foi o mais citado como ferramenta valorizada pelos alunos nas atividades letivas, com $41 \%$ dos docentes alegando que os alunos gostam bastante do aplicativo. Questionados em que medida cada um dos serviços/aplicações da Tabela 1 seria compatível com suas estratégias pedagógicas/letivas, os docentes julgaram que os Blogs seriam $27 \%$ muito compatíveis e $23 \%$ pouco compatíveis; o Facebook é visto como compatível por $76 \%$ dos professores, assim como o Google+ (67\%), o Skype (48\%) e o Youtube (76\%). No caso específico dos docentes de Medicina, 75\% acreditam ser o Youtube muito útil para suas aulas. Em relação a ter alunos como amigos no Facebook, 43\% dos docentes aprovam a ideia, 38\% são indiferentes e $14 \%$ acham ser ruim. Especificamente os professores de Medicina registraram 50\% como bom, $25 \%$ indiferentes e $25 \%$ como ruim.

Os resultados indicam que o grupo dos alunos tem mais afinidades com as redes sociais digitais que os docentes, até por serem de uma geração mais nova e, portanto, nativos digitais, enquanto os professores são migrantes tecnológicos tentando conhecer e, na medida do possível, incorporar as ferramentas que julgam ser úteis. Os dados revelam que o Youtube e o Facebook são as redes mais conhecidas, utilizadas e referenciadas pelos dois grupos. Se compararmos a quantidade de horas gastas no Facebook por ambos os grupos, veremos que os alunos são os que estão mais presentes nessa rede social, embora em ambos os grupos pesquisados (docentes e discentes) a maioria acesse a rede com frequência.

Os dois segmentos pesquisados indicaram que o Facebook possui ferramentas que podem ser utilizadas para fins pedagógicos, principalmente a criação de grupos e o compartilhamento de informações dadas em sala de aula. Como boa parte dos professores adotou os vídeos do Youtube como parte integrante de suas aulas, esta plataforma é conhecida, aceita e bem vista pelos dois grupos pesquisados.

Em relação a serem amigos no Facebook, os alunos aceitam mais essa ideia do que os professores, embora em ambos os grupos as vantagens sejam maiores que as desvantagens nesse relacionamento. A questão da privacidade foi a preocupação levantada por ambos.

Com base na literatura sobre o tema e o resultado da pesquisa com professores e alunos da área da saúde, pudemos verificar que os dois segmentos podem se beneficiar com a utilização da tecnologia ligada às atividades de ensino e aprendizagem. Por questão de necessidade, parte dos professores vem aprendendo a utilizar e adotando algumas ferramentas que resultam em melhora na qualidade de apresentação das aulas e podem facilitar o aprendizado por parte dos alunos. Na presente pesquisa, identificamos que o Google+, o Youtube e o Facebook são os aplicativos que os docentes reconhecem como úteis e, de alguma forma, já incorporaram - principalmente os recursos de vídeo no Youtube - nas aulas. Alguns professores indicaram utilizar o recurso de disponibilizar links e arquivos em seu perfil no Facebook para complementar a aula. Os docentes necessitam ter a tecnologia como aliada e não como concorrente, usando suas potencialidades para melhorar a qualidade do ensino.

Por parte dos alunos, até em função de pertencerem a uma geração mais conectada, o grau de conhecimento das diversas ferramentas da Web 2.0 é maior, estão mais acostumados a utilizá-las diariamente, e parte deles as incorporou como forma de compartilhar aula, discutir conteúdos, reunir os colegas de sala em grupos de trabalho, principalmente na plataforma do Facebook. A tendência, com o aumento da adoção de redes sociais por parte dos alunos conectados de hoje, é que aqueles que optarem pela carreira do ensino passem a utilizar as mídias sociais digitais para as atividades com seus alunos. Araújo, Batista e Gerab ${ }^{12}$ lembram ser importante realçar que pensar no ensino de graduação em Saúde e implementar novos cenários de aprendizagem implicam discutir as condições estruturais (recursos físicos, materiais, humanos e financeiros), descortinando-se possibilidades nos movimentos de parceria com a comunidade e a instauração de processos permanentes de reflexão sobre o fazer docente.

No que tange ao relacionamento entre os diferentes grupos, sobretudo no Facebook, a pesquisa mostra que a questão da privacidade é a parte que mais preocupa tanto aos professores quanto aos alunos. Enquanto boa parte aprova ou se mostra indiferente a ter amigo aluno ou professor no Facebook, alguns alunos relataram não se sentir confortáveis com a possibilidade de o professor poder acompanhar suas postagens sobre assuntos da aula ou fora dela. Muitos docentes concordam que a relação aluno-professor deve terminar na escola e a vida particular deve ser preservada. Mazer et al. ${ }^{13}$, em pesquisa realizada com 129 universitários americanos, relataram que os estudantes tendem a atribuir graus maiores de 
confiança e de qualidade profissionais aos docentes que se expõem mais na rede social, sem se preocupar em restringir seus dados pessoais.

A Plataforma Facebook oferece a possibilidade de regular o grau de privacidade de fotos e postagens, bastando que o professor (ou o aluno) estabeleça o que pode ou não ser visto pelos colegas. Para os grupos fechados, criados para ampliar a aula dentro do Facebook, há a possibilidade de aceitar pessoas para o grupo sem necessariamente tê-las no status de "amigo", o que pode ser uma solução para o problema relatado de falta de privacidade. Talvez a solução esteja justamente na capacitação de ambos os segmentos na utilização correta da ferramenta e aceitar ou não o aluno e o professor como "amigo" no Facebook continue sendo uma opção pessoal.

\section{REFERÊNCIAS}

1. Brasil. Presidência da República. Secretaria de Comunicação Social. Pesquisa brasileira de mídia 2015: hábitos de consumo de mídia pela população brasileira. Brasília: Secom, 2014.

2. Recuero R. Redes sociais na Internet. Porto Alegre. Editora Sulina, 2009

3. Mondini LC, Domingues MJCS, Correia RB, Mondini VED. Redes sociais digitais: uma análise de utilização pelas instituições de ensino superior do sistema ACAFE de Santa Catarina. Rev Eletrôn Ciênc Adm. 2012:11(1):48-60. http://dx.doi.org/10.5329/RECADM.20121101003

4. Shah V, Subramanian S, Rouis S, Limayem M. A Study on the impact of Facebook usage on student's social capital and academic performance. AMCIS. 2012;27.

5. Magro M, Ryan K, Ryan S, Sharp J. Facebook's use in higher education. AMCIS. 2012;10.

6. Hew KF. Student's and teachers' use of Facebook. Comput Human Behav. 2011;27(2):662-76.

http://dx.doi.org/10.1016/j.chb.2010.11.020

7. Choi A. Use of Facebook group feature to promote student collaboration. American Society for Engineering Education. ASEE Southeast Section Conference, 2013.
8. Barczyk CC, Duncan DG. Facebook in higher education courses: An Analysis of Students' Attitudes, Community of Practice, and Classroom Community. Int Bus Manage. 2013;6(1):1-11. http://dx.doi.org/10.3968\%2Fj.ibm.1923842820130601.1165

9. Chatterjee S. Facebook as a tool in higher education and the gender issue: a survey among students in Bankura. Bhatter Coll $J$ Multidiscip Stud. 2012;2:89-94.

10. Roblyer MD, McDaniel M, Webb M, Herman J, Witty JV. Findings on Facebook in higher education: A comparision of college faculty and students uses and perceptions of social networking sites. Internet High Educ. 2010;13(3):134-40.

http://dx.doi.org/10.1016/j.iheduc.2010.03.002

11. Bicen $\mathrm{H}$, Uzunboylu $\mathrm{H}$. The Use of Social Networking Sites in Education: a case study of Facebook. J Univers Comput Sci. 2013;19(5):658-71. http://dx.doi.org/10.3217/jucs-019-05-0658

12. Araújo EC, Batista SH, Gerab IF. A produção científica sobre docência em saúde: um estudo em periódicos nacionais. Rev Bras Educ Méd. 2011;35(4):486-92.

13. Mazer JP, Murphy RE, Simonds CJ. The effects of teacher self-disclosure via Facebook on teacher credibility. Learn Media Technol. 2009;34(2):175-83.

http://dx.doi.org/10.1080/17439880902923655 